\title{
Controle da utilização de ingredientes não cárneos para injeção e marinação de carnes
}

\author{
Control of non meat ingredients for meat injection and marination
}

\author{
Heitor Daguer ${ }^{\mathrm{I}}$ Michel Tavares Quinteiro Milcent Assis ${ }^{\mathrm{II}}$ Luciano dos Santos Bersot ${ }^{\mathrm{II}}$
}

\section{- REVISÃO BIBLIOGRÁFICA -}

RESUMO

\begin{abstract}
O crescimento da produção e consumo de carne têm sido acompanhados da diversificação de produtos processados, com maior elaboração de itens de conveniência, praticidade e valor agregado, em detrimento da comercialização de cortes in natura. Fosfatos e proteínas não cárneas, sobretudo as da soja e do soro de leite, figuram entre os ingredientes mais usados para marinar carnes, melhorando sua textura e promovendo a retenção de líquidos que podem trazer aumento do rendimento de fabricação e benefícios sensoriais para o consumidor. Nessa tecnologia, os principais processos empregados são a injeção e o massageamento da carne. No entanto, práticas abusivas devem ser coibidas pela fiscalização, impondo limites à incorporação de água pelo produto final e à utilização de ingredientes não cárneos. No presente artigo, são revisados aspectos da utilização desses ingredientes, ressaltando a importância da disponibilidade de técnicas analíticas adequadas ao controle de produtos injetados e marinados.
\end{abstract}

Palavras-chave: marinação, ingredientes não cárneos, controle.

\section{ABSTRACT}

Meat production and consumption growth has been accompanied by a wide diversification of processed products, while the trading of non-processed meat has decreased. Phosphates and non-meat proteins, mainly soy and whey proteins, are widely used to marinate meat, improving its texture and promoting the fluids retention that can bring sensorial benefits to the consumers and improve producers' yield. On this technology, the main processes employed are the injection and the tumbling of raw materials. However, some fraudulent practices must be avoided by the meat inspection service, setting limits to the replacement of meat proteins by water and non-meat ingredients. The present article reviewed the main aspects of the use of such ingredients enlightening the importance of appropriate analytical techniques to control injected, and marinated products.

Key words: marination, non-meat ingredients, control.

\section{INTRODUÇÃO}

O desenvolvimento de novos produtos mais competitivos e com valor agregado tem se mostrado como fator decisivo na participação de empresas menores no mercado. A fim de atender à demanda dos consumidores, em associação ao crescimento da população urbana brasileira, mudanças significativas têm ocorrido nos padrões de consumo alimentar, entre elas, a redução do consumo de alimentos que demandam mais tempo para preparo e o aumento do consumo de alimentos preparados (SCHLINDWEIN \& KASSOUF, 2006).

IMinistério da Agricultura, Pecuária e Abastecimento, Laboratório Nacional Agropecuário (LANAGRO/RS), Serviço Laboratorial Avançado em Santa Catarina, Rua João Grumiché, 117, 88102-600, São José, SC, Brasil. E-mail: heitor.daguer@agricultura.gov.br. Autor para correspondência.

"Ministério da Agricultura, Pecuária e Abastecimento, Superintendência Federal em Santa Catarina, Serviço de Inspeção de Produtos de Origem Animal, São José, SC, Brasil.

IIIPrograma de Pós-graduação em Tecnologia de Alimentos, Centro Politécnico, Universidade Federal do Paraná (UFPR), Curitiba, PR, Brasil. 
A técnica de marinar carnes, que consiste na incorporação de soluções com ingredientes funcionais e condimentos ao músculo, tem gerado uma grande variedade de produtos, aumentando em proporção ao crescimento da demanda por produtos cárneos processados. A marinação vem se desenvolvendo desde os anos 80, principalmente nos Estados Unidos, no Reino Unido, na Noruega, na Suécia e na Finlândia, onde é regulamentada e resulta em produtos bem-aceitos pelos consumidores, que reconhecem o incremento do sabor e a textura. Com isso, o impacto da utilização de soluções para incremento das características sensoriais da carne injetada/marinada tem demandado investigação científica relevante (SHEARD \& TALI, 2004; BAUBLITS et al., 2006; BJÖRKROTH, 2005; HAYES et al., 2006; GOODING et al., 2009; SCHIRMER et al., 2009).

No Brasil, há crescente oferta de produtos injetados e marinados, principalmente à base de carnes de aves e suína, com menor participação da bovina. No entanto, como a fabricação desses produtos não está ainda regulamentada, a utilização de ingredientes não cárneos e a injeção de salmouras muitas vezes são irregulares, ocorrendo na forma de práticas comerciais enganosas, sem que se forneçam esclarecimentos sobre a verdadeira composição dos produtos aos consumidores. Recentemente, o Departamento de Inspeção de Produtos de Origem Animal (DIPOA), do Ministério da Agricultura, Pecuária e Abastecimento (MAPA), órgão responsável pela normatização técnicosanitária de alimentos de origem animal no Brasil, proibiu a fabricação de cortes de frango temperados ou marinados em que se utiliza o processo de injeção, até que haja métodos eficazes para o controle de fraudes (BRASIL, 2010).

Com o objetivo de revisar os principais aspectos de ingredientes não cárneos utilizados em produtos marinados e injetados, o presente trabalho ressalta a importância de haver disponíveis técnicas analíticas adequadas à detecção e quantificação desses ingredientes, de forma a disciplinar a fabricação desses produtos e a viabilizar o controle do processo pela fiscalização.

\section{Marinação de carnes e enhancement}

A expressão "marinação" se origina de línguas latinas, que se referem dessa forma à técnica de embeber carnes em salmouras. Embora ocorra bastante variação entre os diversos países em que é aplicada, tem-se por marinação a adição de sal, fosfatos e condimentos à carne (BJÖRKROTH, 2005). Inicialmente utilizada como prática culinária, a marinação se estendeu ao nível industrial, tendo sido utilizada há décadas pela indústria de carne de frango. Mais recentemente, tem se estendido à carne suína e, em menores proporções, à carne bovina, sendo obtidos avanços tecnológicos e fazendo com que a comercialização de carne in natura venha cedendo lugar às carnes semipreparadas, adicionadas de soluções (XIONG, 2005; SCHIRMER et al., 2009). O uso de ingredientes não cárneos é defendido como forma simples de agregar valor, gerando diversos estudos (VOTE et al., 2000; SHEARD \& TALI, 2004; BAUBLITS et al., 2006; HAYES et al., 2006; SCHIRMER et al., 2009).

A marinação é aplicada de forma estática ou dinâmica. A forma estática é feita por imersão da carne na salmoura, quando os ingredientes penetram gradativamente por difusão, sem aplicação de força. No processo dinâmico, empregam-se a injeção e o massageamento da carne. Para injeção, utiliza-se uma "injetora de salmoura", que consiste de uma esteira transportadora das carnes e de um ou dois jogos de agulhas ocas e perfuradas, ligadas a um sistema de bombeamento dotado de um reservatório para as soluções para injeção. Há vários tipos de injetoras, com sistemas de pressão e agulhas em quantidades e calibres diversos (PRÄNDL et al., 1994). A penetração perpendicular das agulhas nas fibras musculares faz com que a solução preparada se distribua pelo tecido muscular. A solução deve estar entre 0 e $5^{\circ} \mathrm{C}$, para segurança alimentar e para propiciar melhor retenção do líquido pelo produto. Entre os fatores que influenciam a uniformidade dos produtos, estão: distância entre agulhas, velocidade de avanço da esteira transportadora (velocidade de injeção), tipo de agulha empregada, distância da esteira programada para descida das agulhas (PRÄNDL et al., 1994; OLIVO, 2006).

O massageamento combinado à injeção promove maior equilíbrio do produto e permite a aplicação de coberturas, molhos e especiarias. A operação é feita em um "tambor" metálico giratório (tumbler), no qual se depositam as carnes e a salmoura, aumentando a incorporação dos ingredientes pela carne (PRÄNDL et al., 1994; BORTOLUZZI, 2006).

Uma tecnologia similar à marinação, denominada enhancement (incremento, melhoria), consiste na injeção de soluções na carne fresca para aumentar a retenção de fluidos durante seu cozimento doméstico, incrementando atributos sensoriais ligados à textura (suculência e maciez). Nesse processo, não são agregados condimentos ou flavorizantes, e o rendimento é maior quando são empregados sal, fosfatos, lactatos, diacetato de sódio, gomas, amidos modificados e proteínas de soja e do soro de leite. A carne injetada tem aparência semelhante à da carne 
fresca, mas difere em valor nutritivo (VN) e composição mineral (BRASHEAR et al., 2002; MURPHYGUTEKUNST \& URIBARRI, 2005; XIONG, 2005; ASSIS, 2009; DAGUER, 2009).

No entanto, as técnicas de injeção e marinação, quando aplicadas pela indústria, ao mesmo tempo em que devem utilizar ingredientes em concentrações suficientes para incrementar atributos sensoriais, não podem gerar efeitos adversos no sabor e na coloração, nem causar maciez excessiva, fatores que podem causar rechaço dos consumidores, e também não devem objetivar a melhora da matéria-prima de má qualidade, sob risco de não surtir os efeitos esperados (MILLER, 1998; SHEARD \& TALI, 2004; BAUBLITS et al., 2006). Na carne injetada, podem formar-se estrias paralelas à musculatura, visíveis na superfície de corte, comprometendo seu aspecto (GOODING et al., 2009). Embora os produtos marinados tenham um mercado potencialmente crescente, a quantificação de sua aceitabilidade em relação à carne in natura ainda é necessária, sendo os consumidores esclarecidos quanto à natureza e às vantagens da carne injetada (BAUBLITS et al., 2006; HAYES et al., 2006).

Ingredientes não cárneos utilizados na injeção e marinação de carnes

Fosfatos

Fosfatos e sal ( $\mathrm{NaCl})$ são utilizados em soluções para marinação, isolados ou combinados, a fim de explorar sua ação sinérgica. Os fosfatos podem ser adquiridos em misturas de diferentes tipos, embora os mais utilizados sejam o pirofosfato, o tripolifosfato e o metafosfato solúvel. A mistura de polifosfatos tem sido recomendada, por trazer bons resultados de rendimento e alta aceitabilidade dos produtos. Para processamento de marinados, são reconhecidos como mais eficazes o pirofosfato e o tripolifosfato (XIONG, 2005; XU et al., 2009).

$\mathrm{Na}$ fibra muscular, os fosfatos despolimerizam os filamentos de miosina e facilitam a dissociação do complexo acto-miosina, aumentando a dissolução proteica e a quantidade de cargas elétricas do sistema e incrementando o aumento da capacidade de retenção de água (CRA) da carne (OFFER \& TRINICK, 1983; XIONG, 2005). No nível microestrutural, os fosfatos atuam principalmente nos discos Z, favorecendo a extração da miosina, o que incrementa a maciez da carne (XIONG, 2005; XU et al., 2009).

Em produtos cárneos, os fosfatos melhoram as características sensoriais pelo aumento da suculência e pela redução da força de cisalhamento, e ainda pelo decréscimo da perda por cozimento (XU et al., 2009). Além disso, aumentam significativamente o
$\mathrm{pH}$, retardam a descoloração pela estabilização da vitamina $\mathrm{C}$ e concedem propriedades antioxidantes (DUŠEK et al., 2003; SHEARD \& TALI, 2004). Por outro lado, o fosfato solúvel, tanto do fosfato adicionado, quanto do fosfato natural da carne, pode esgotar íons metálicos importantes à nutrição, como cálcio e magnésio, daí a importância de se respeitar o limite legal (DUŠEK et al., 2003).

$\mathrm{Na}$ carne tratada com fosfatos, agentes precursores de sabor podem ser solubilizados e drenados, durante e imediatamente após a injeção, fazendo com que o aparecimento de sabores estranhos fique mais aparente, pois a intensidade do sabor próprio da carne é inversamente proporcional à concentração do aditivo (SHEARD et al., 1999; VOTE et al., 2000).

Extensores (proteínas não cárneas)

Extensores são proteínas alternativas ou misturas de proteínas que permitem substituir em parte as proteínas naturais da carne, contribuindo para a obtenção de produtos de qualidade similar, a custo mais baixo (OLIVO, 2006). No Brasil, há ampla disponibilidade de extensores, sendo comum a combinação de proteínas não cárneas com gomas e fosfatos (DAGUER, 2009).

As proteínas funcionais são atraídas pelas proteínas da carne, formando uma malha proteica interna que estabiliza o produto. Além de incrementar a umidade natural da carne, à medida que ocorre a adição de soluções em marinados, os extensores aumentam o rendimento de fabricação, pois, no produto final, há acréscimo de peso em relação ao original (OLIVO, 2006).

A legislação brasileira especificou limites para a adição de ingredientes não cárneos com a finalidade de promover extensão, mas sua detecção e quantificação ainda se constituem um problema para a fiscalização, devido à escassez de metodologias analíticas apropriadas para determinação desses ingredientes (BELLOQUE et al., 2002). De acordo com a tabela 1, a utilização de proteínas não cárneas está permitida em teores que variam de 2 a $4 \%$ (BRASIL, 2000a; BRASIL, 2000b; BRASIL, 2000c; BRASIL, 2000d; BRASIL, 2001). Em alguns produtos, como copa, jerked beef, presunto tipo Parma e presunto cru, sua adição não é permitida; em outros, como salames e linguiça colonial, é permitida a adição de proteínas lácteas, mas não de proteínas vegetais (BRASIL, 2000d).

Embora as proteínas de soja sejam as mais adicionadas aos produtos cárneos, outras proteínas podem ser empregadas, sejam de origem animal, como os caseinatos, as proteínas à base de soro de leite, o plasma sanguíneo e a ovalbumina; sejam de origem 
Tabela 1 - Limites máximos de adição de proteínas não cárneas à formulação de produtos cárneos, com a finalidade de promover extensão, de acordo com a legislação brasileira.

\begin{tabular}{lcl}
\hline Produtos cárneos & Adição máxima & \multicolumn{1}{c}{ Restrições } \\
\hline $\begin{array}{c}\text { Mortadela, salsicha, hambúrguer, kibe, } \\
\text { almôndega e empanados. }\end{array}$ & $4,0 \%$ & $\begin{array}{l}\text { Proibida a adição em: } \\
\text { a) mortadelas dos tipos Bologna e Italiana (permitido uso } \\
\text { de proteínas lácteas nesses produtos); } \\
\text { b) salsichas Viena e Frankfurt. }\end{array}$ \\
Patês & $3,0 \%$ & $\begin{array}{l}\text { Proibida a adição em lingüiças Toscana, Calabresa, } \\
\text { Portuguesa, Blumenau e Colonial. }\end{array}$ \\
$\begin{array}{l}\text { Lingüiças, bacon e apresuntado. } \\
\begin{array}{l}\text { Paleta cozida, pepperoni, presunto, presunto } \\
\text { cozido e lombo suíno. }\end{array}\end{array}$ & $2,5 \%$ & Proibida a adição em Presunto cozido "superior". \\
\hline
\end{tabular}

FONTE: Ministério da Agricultura, Pecuária e Abastecimento (BRASIL, 2000a; BRASIL, 2000b; BRASIL, 2000c; BRASIL, 2000d; BRASIL).

vegetal, como o glúten do trigo, o amendoim, a colza, as sementes de algodão e do girassol, o feno-grego (alforva) e os tremoços (Lupinus spp.) (JANSSEN et al., 1987; SZERMAN et al., 2007). Em produtos cozidos cujas formulações tenham baixo conteúdo de carne, o uso de proteínas não cárneas se destaca por suprir sua baixa capacidade de emulsificação, prevenindo a coalescência da gordura durante o tratamento térmico (BELLOQUE et al., 2002; CASTRO-RUBIO et al., 2005). Algumas proteínas não cárneas podem também ser utilizadas como substituintes da gordura, devido a sua habilidade em ligar-se à água, formando géis e atendendo a demandas por dietas mais saudáveis (CASTRO et al., 2007).

Proteínas da soja

A soja e seus derivados têm recebido atenção devido à quantidade e qualidade de sua proteína, sendo considerada, entre os vegetais, o melhor substituto de produtos de origem animal. As proteínas de soja têm sido utilizadas como ingredientes funcionais e nutricionais em produtos de panificação, fórmulas infantis, formulações para nutrição clínica, suplementos proteicos, produtos à base de peixe, molhos, sopas e como substitutas em alimentos lácteos e cárneos (GENOVESE \& LAJOLO, 2001; SEIBEL \& BELÉIA, 2008).

O processamento da soja origina diferentes matérias-primas, como as farinhas, os extratos hidrossolúveis e as proteínas texturizadas utilizadas na dieta ocidental. Nos últimos anos, a procura por derivados da soja tem aumentado pela divulgação de benefícios à saúde, atribuídos ao seu consumo (GÓESFAVONI et al., 2004). Segundo o Codex Alimentarius, produtos proteicos da soja são preparados com grãos da leguminosa (sementes de Glycine max), mediante procedimentos como a separação e a extração, que eliminam ou reduzem os constituintes não proteicos, obtendo-se conteúdo proteico de 50 a $65 \%$ (farinha proteica de soja), 65 a $90 \%$ (concentrado proteico de soja) ou de no mínimo 90\% (proteína isolada de soja).

A disponibilidade de diversos tipos de proteína de soja facilita sua incorporação aos produtos cárneos, sendo a proteína concentrada a mais usada, seguida da proteína texturizada e da proteína isolada de soja. A hidrólise das proteínas da soja melhora o desempenho dessas propriedades, propiciando interação ainda maior com as proteínas miofibrilares (XIONG, 2005). Em produtos cárneos, a soja melhora a textura e capacidade emulsificante, intensifica sua aparência, sua firmeza, sua suculência, sua fatiabilidade e seu rendimento de cocção, reduz o custo de formulação e pode substituir a gordura animal (CASTRO-RUBIO et al., 2005; XIONG, 2005). Pode retardar a rancificação, devido à habilidade de seus ácidos polifenóicos e isoflavonoides (PIHLANTO, 2006). Por outro lado, a soja de baixa qualidade pode alterar o sabor normal dos produtos. Estudos sensoriais têm sugerido que o concentrado proteico de soja seja empregado em teores máximos de 3 a $4 \%$, a fim de evitar alteração do produto pelo sabor indesejado da soja ou beany flavour - (PEDERSEN, 1995). Para indivíduos alérgicos, a ingestão de soja ou outras proteínas não cárneas pode representar risco, daí a importância do controle de sua utilização e da informação expressa no rótulo (MELLENTHIN \& GALENSA, 1999).

Proteínas do soro de leite

Antes considerado um resíduo de baixo valor econômico, o soro de leite tem sido muito empregado como ingrediente funcional, face as suas propriedades físico-químicas e biológicas. Devido ao 
alto teor de lactose (>75\%) em seus sólidos totais, é considerado um dos maiores poluentes que emanam da indústria de alimentos. A aplicação de processos com membranas tem contribuído para o desenvolvimento de compostos à base de soro de leite, com altos teores de proteína e baixos teores de gordura, como o concentrado proteico e o isolado proteico, expandindo, assim, sua aplicação (SMITHERS, 2008). O concentrado proteico de soro de leite (CPSL) pode ter de 35 a $80 \%$ de proteína, diversos níveis de gordura e minerais (SAMMEL et al., 2007). Metade dos sólidos do leite aparece no soro, junto com a totalidade da lactose e cerca de $20 \%$ das proteínas. A $\alpha$-lactalbumina e ß-lactoglobulina são as principais proteínas, perfazendo 70 a $80 \%$ do total de proteínas. São também encontradas albumina, imunoglobulinas, lactoferrinas e enzimas (MCINTOSH et al., 1998).

Os CPSL têm sido adicionados a alimentos para modificar propriedades por meio da gelatinização, do aumento da viscosidade, da estabilização de emulsões, entre outras (ANTUNES et al., 2003; SAMMEL et al., 2007). Em produtos cárneos, o uso de proteínas do leite tem alto potencial, gerando boa qualificação à análise sensorial e aumento da CRA e do VN (HAYES et al., 2006; SZERMAN et al., 2007).

O soro fluido também pode ser usado na industrialização da carne, tendo sido recentemente empregado com sucesso na fabricação de mortadelas em substituição de até $100 \%$ da água utilizada na formulação do produto, sem alterar suas características físico-químicas e sensoriais (TERRA et al., 2009).

Sabe-se, ainda, que as proteínas do soro possuem atividade anticarcinogênica e, nos produtos aos quais são adicionadas, inibem a rancificação, contribuindo para aumentar sua estabilidade (PEÑARAMOS \& XIONG, 2003; PIHLANTO, 2006; DAGUER, 2009). Devido à alta concentração de lactose, formamse componentes antioxidantes derivados da reação de
Maillard durante o cozimento, importantes no controle da rancificação, principalmente em produtos cozidos (PEÑA-RAMOS \& XIONG, 2003).

\section{Gomas e açúcares}

Outros ingredientes não proteicos são autorizados para emprego em produtos cárneos com a finalidade de promover a extensão, embora estejam oficialmente classificados como espessantes (Tabela 2). Muitas vezes, são utilizados em combinação com proteínas não cárneas, amidos, maltodextrinas e outros carboidratos, aumentando a imobilização da água (HOOGENKAMP, 2005). A utilização de açúcares em pequenas quantidades confere sabor e desenvolvimento de cor em produtos marinados, atenuando o sabor do sal e de componentes de sabor amargo (PRANDL et al., 1994).

A carragena é a goma mais utilizada em produtos cárneos. Sozinha ou combinada, vem sendo adicionada a muitos produtos, devido a sua habilidade em formar gel, reter água e fornecer textura desejada (PIETRASIK, 2003). A carragena é obtida da extração de algas marinhas vermelhas (gêneros Chondrus, Eucheuma e Gigartina) e sua estrutura consiste de polímeros sulfatados constituídos de unidades de galactose e anidrogalactose. As carragenas têm forte caráter aniônico e reagem com polieletrólitos catiônicos, em particular as proteínas (MULTON, 1988). A carragena melhora a textura e a CRA dos produtos cárneos e, quando associada a proteínas não cárneas, incrementa os resultados. As proteínas solúveis são responsáveis pela formação de uma matriz de gel tridimensional, e a carragena, após estabilização, fica localizada nos espaços intersticiais dessa rede proteica (VERBEKEN et al., 2005).

Controle da utilização de ingredientes não cárneos em carnes

Técnicas analíticas para controle da utilização de proteínas não cárneas

Tabela 2 - Limites máximos de adição, por categoria de produto cárneo, de ingredientes não cárneos (gomas) que têm por finalidade promover extensão, de acordo com a legislação brasileira.

\begin{tabular}{|c|c|c|}
\hline Categoria de produto cárneo & Carragena (INS 407) & $\begin{array}{l}\text { Goma-guar (INS 412), goma-Xantana } \\
\text { (INS 415) e goma-garrofin (INS 410) }\end{array}$ \\
\hline Produtos cárneos frescos, embutidos ou não. & $0,3 \%$ & NP \\
\hline Produtos cárneos cozidos, embutidos ou não. & $0,5 \%$ & $0,3 \%$ \\
\hline Produtos cárneos salgados cozidos. & $0,5 \%$ & $0,3 \%$ \\
\hline Produtos cárneos em conserva ou semiconserva. & $0,5 \%$ & $0,3 \%$ \\
\hline
\end{tabular}

INS = Sistema Internacional de Numeração de Aditivos; NP = Não permitido.

FONTE: Ministério da Agricultura, Pecuária e Abastecimento (BRASIL, 2007). 
Qualquer método que detecte diferenças na estrutura primária das proteínas pode ser aplicado para avaliar a presença de proteínas não cárneas em produtos cárneos. Embora algumas técnicas sejam bastante eficientes, podem ser onerosas e extremamente demoradas. O desenvolvimento de produtos cárneos adicionados dessas proteínas não foi acompanhado pelo desenvolvimento de técnicas analíticas para controle de sua utilização, o que indica a necessidade de realização de pesquisas (BELLOQUE et al., 2002). Métodos eletroforéticos, imunoquímicos e cromatográficos têm sido utilizados, embora não sejam aplicáveis a todos os produtos, apresentando-se falhos para a análise de produtos cozidos e esterilizados, devido às alterações sofridas pelas proteínas durante o aquecimento (BELLOQUE et al., 2002; VELOSO et al., 2002).

Por meio de hidrólise parcial, é possível fragmentar as proteínas em pontos específicos de sua estrutura e produzir ampla variedade de peptídeos que representam, cada um, uma porção da molécula original. Quando a reação enzimática se completa, o modelo de peptídeos obtidos é característico da proteína hidrolisada, e os digestos de soja contêm grupos de peptídeos carregados positivamente, facilmente distinguíveis daqueles da carne (BAILEY, 1976). AGATER et al. (1986) analisaram peptídeos de produtos cárneos termicamente processados adicionados de até $2 \%$ de soja, demonstrando a aptidão da técnica para detecção do ingrediente.

A Association of Official Analytical Chemists (AOAC) propõe a utilização de duas técnicas para controle do emprego de soja em produtos cárneos (AOAC, 2005). A primeira, baseada na microscopia de um extrato alcalino sob luz polarizada, tem sido usada desde 1913 para detecção da soja em concentrações próximas a 1\% (método 913.01). A segunda consiste de um imunoensaio enzimático (ELISA) semiquantitativo, podendo ser quantitativo se a natureza da soja utilizada é conhecida (método 988.10).

Com ELISA, demonstrou-se a ocorrência de fraudes em produtos comercializados na Espanha, revelando adições de até $40 \%$ de soja em embutidos (GONZÁLEZ-CÓRDOVA et al., 1998). Diversas referências propõem o emprego de técnicas em alternativa ao ELISA, que, considerado de acuidade limitada, moroso, caro e complexo, tem sido bastante criticado (LEITNER et al., 2006). Comparando-se o ELISA à cromatografia líquida de alta eficiência (CLAE) para quantificação de proteínas da soja em produtos cárneos cozidos, não são observadas diferenças significativas entre as técnicas (CASTRO-RUBIO et al., 2005).
Na União Europeia, a importação de soja transgênica misturada à soja não modificada geneticamente tem gerado receios nos consumidores, fazendo com que a definição de técnicas para deteç̧ão de soja e outras proteínas vegetais em alimentos ganhasse novo vigor (MELLENTHIN \& GALENSA, 1999). A reação em cadeia da polimerase (PCR) também pode ser empregada para produtos cárneos, detectando e quantificando a utilização de soja transgênica em índices abaixo de $0,1 \%$ (TASKI-AJDUKOVIC et al., 2009).

Em produtos adicionados de tecido conjuntivo, a determinação da hidroxiprolina é importante para a estimativa da proteína cárnea efetivamente empregada na formulação. Dessa forma, o perfil de aminoácidos dos produtos pode auxiliar na sua análise, determinando sua qualidade proteica. Uma alternativa à determinação de proteínas não cárneas é a aplicação de cálculos matemáticos baseados no conhecimento prévio da formulação do produto, chegando à quantidade de proteína cárnea pela diferença do porcentual de proteína total da quantidade de proteínas não cárneas adicionadas e da proteína do tecido conjuntivo (PRÄNDL et al., 1994). Por outro lado, a soja também pode conter hidroxiprolina, limitando o uso do perfil de aminoácidos e do cálculo do colágeno total para quantificação de tecido conjuntivo (ZARKADAS et al., 1993). Isso justifica a necessidade de haver disponíveis técnicas analíticas não somente para quantificação de proteína cárnea efetivamente existente, como também para quantificar as proteínas não cárneas empregadas na formulação.

Eletroforese de proteínas

A eletroforese é útil para detectar e quantificar a presença de ingredientes estranhos à composição de diversos produtos (ABDEL-AZIZ et al., 1997; SOUZA et al., 2000). SDS-PAGE (eletroforese em gel de poliacrilamida na presença de dodecil-sulfato de sódio) também é utilizada para avaliar a degradação e a oxidação proteica e para avaliar a cura de produtos específicos, como presuntos de designação de origem controlada e, ainda, durante a aplicação de tratamento térmico (LARREA et al., 2006; XIA et al., 2009). Pode também ser empregada para identificação de espécies, para detecção de adulteração em produtos lácteos e para caracterização de compostos proteicos (VELOSO et al., 2002). Em produtos cárneos adicionados de proteínas não cárneas, nem sempre se consegue a separação adequada das proteínas à eletroforese. No caso de SDS-PAGE, a técnica parece ser mais adequada à detecção de proteínas lácteas, pois nem sempre é capaz de separar as proteínas de soja (DAGUER et al., 2010b). 
Alternativamente, a eletroforese capilar (EC) tem surgido como uma nova alternativa à análise de alimentos suspeitos de fraudes (sobretudo lácteos), detectando e quantificando proteínas estranhas a sua composição (VALLEJO-CORDOBAet al., 2005).

\section{Cromatografia}

Métodos cromatográficos também são utilizados para controle da utilização de proteínas não cárneas em produtos cárneos, baseando-se na composição e sequência de peptídeos e de aminoácidos ou na detecção direta de ingredientes (MELLENTHIN \& GALENSA, 1999; CASTRO-RUBIO et al., 2005; CASTRO et al., 2007). CASTRO et al. (2005) e CASTRO et al. (2007) desenvolveram um método de CLAE para quantificação de soja em produtos cárneos cozidos, detectando níveis de 0,08 a 1,89\% da leguminosa em produtos comercializados na Espanha. Em comparação com o ELISA, com CLAE obtiveram-se maior rapidez e menor custo.

Para a fiscalização de carnes, na análise de produtos adicionados de proteína vegetal, a coleta rotineira de amostras dos extensores utilizados pelas fábricas tem sido proposta, de forma a determinar seu perfil de isoflavonas. A quantificação de soja é mais precisa quando o conteúdo dessas substâncias na proteína vegetal empregada é conhecido (MELLENTHIN \& GALENSA, 1999).

A utilização de cromatografia para controle da utilização de ingredientes não cárneos na composição de produtos cárneos é bastante conveniente, por ser de realização relativamente rápida, sensível e específica, Embora tenha alto custo, permite quantificar proteína cárnea e não cárnea, detecta e quantifica diversos ingredientes e assim avalia de forma eficaz a conformidade de produtos. Quando combinada à espectrometria de massas, permite ainda melhor identificação de ingredientes, com novos marcadores (LEITNER et al., 2006).

Determinação de substâncias não proteicas

Tecidos vegetais contêm substâncias não encontradas nos tecidos animais que podem ser aproveitadas para a análise de constituintes não proteicos de alguns ingredientes. Como tecidos vegetais e animais possuem reação cruzada praticamente nula, métodos imunoquímicos também podem ser utilizados para estimar a quantidade de proteínas adicionadas aos produtos cárneos (BAILEY, 1976; BERKOWITZ \& WEBERT, 1987).

O ácido fítico (ácido inositol-hexafosfórico) é uma forma importante de armazenamento de fosfato na soja. Esse composto característico dos vegetais pode funcionar como marcador qualitativo, pois sua presença em qualquer quantidade significa a presença de material vegetal (BERKOWITZ \& WEBERT, 1987).

Compostos fitoquímicos, como as antocianinas dos frutos vermelhos, os flavonóis das folhas e as isoflavonas da soja são substâncias vegetais não nutrientes que possuem atividade biológica promotora da saúde, com ação antioxidante, antiinflamatória e hipocolesterolêmica, o que tem gerado estudos para sua quantificação em matrizes biológicas, grãos de soja, suplementos nutricionais e produtos alimentícios e farmacêuticos (GENOVESE \& LAJOLO, 2001; GÓES-FAVONI et al., 2004). Em produtos cárneos, as isoflavonas são uma alternativa à quantificação de soja por CLAE ou EC (VALLEJOCORDOBA et al., 2005; DAGUER et al., 2010a). Embora semelhantes, os resultados obtidos por CLAE têm melhores repetibilidade e sensibilidade em comparação à EC (MELLENTHIN \& GALENSA, 1999).

Controle do uso de fosfatos em carnes

Em todo o mundo, são impostos limites para utilização de fosfatos em alimentos. A legislação brasileira permite o emprego de no máximo $0,5 \%$ de fosfatos em produtos cárneos (BRASIL, 2007). Em algumas populações, o consumo de fósforo aumentou sem que houvesse, paralelamente, o aumento do consumo de cálcio, conduzindo ao desequilíbrio desses minerais, o que pode prejudicar a solidez do esqueleto (DURAND, 2002). Em pacientes renais crônicos, a ingestão de fósforo deve ser limitada, devendo ser dada atenção especial à rotulagem dos produtos cárneos contendo fosfatos (MURPHY-GUTEKUNST \& URIBARRI, 2005).

A quantidade de fosfato adicionado é determinada pela diferença entre o fosfato total e o fosfato proteico. O método mais usado para determinação de fosfato total em alimentos é o espectrofotométrico das cinzas, enquanto o fosfato proteico é calculado pela concentração de nitrogênio pelo método Kjeldahl. Outras técnicas aplicáveis são CLAE de troca iônica, detecção colorimétrica póscoluna de molibdato, EC e isotacoforese capilar (SEKIGUCHI et al., 2000; DURAND, 2002; DUŠEK et al., 2003).

\section{CONCLUSÃO}

A injeção e a marinação de carnes são tecnologias emergentes que podem trazer benefícios aos produtos, desde que respaldadas na legislação e de que os produtos sejam bem-aceitos pelos consumidores. Todas as informações necessárias à 
garantia dos direitos do consumidor, previstas na legislação específica, devem ser prestadas explicitamente quando de sua comercialização. As principais técnicas que podem ser aplicadas e que demandam pesquisa para validação em produtos cárneos são SDS-PAGE, CLAE, espectrometria de massas e EC. A validação de técnicas analíticas compatíveis ao controle dos ingredientes utilizados é essencial para que a fiscalização desses produtos seja possível, disciplinando sua fabricação.

\section{REFERÊNCIAS}

ABDEL-AZIZ, S.A. et al. Chemical composition and levels of nonmeat proteins in meat brands extended with soy protein concentrate. Food Chemistry, v.60, n.3, p.389-395, 1997. Disponível em: <http://dx.doi.org/10.1016/S0308-8146(96)00357-3>. Acesso em: 07 mar. 2009. doi: 10.1016/S0308-8146(96)00357-3.

AGATER, I.B. et al. The determination of soya and meat protein in raw and processed meat products by specific peptide analysis. An evaluation. Journal of the Science of Food and Agriculture, v.37, n.3, p.317-331, 1986.

ANTUNES, A.E.C. et al. Perfil de textura e capacidade de retenção de água de géis ácidos de concentrado proteico de soro de leite. Ciência e Tecnologia de Alimentos, v.23 (supl.), p.183-189, 2003. Disponível em: <http://www.scielo.br/ scielo.php? script=sci_arttext \& pid = S $0101-$ $20612003000400034 \& \operatorname{lng}=$ pt\&nrm=iso $>$. Acesso em: 29 maio, 2009. doi: 10.1590/S0101-20612003000400034.

AOAC - ASSOCIATION OF OFFICIAL ANALYTICAL CHEMISTS. Official methods of analysis of AOAC international. 18.ed. Gaithersburg, 2005. Cap.39, p.1-24.

ASSIS, M.T.Q.M. Avaliação físico-química de filés de peito de frango adicionados de sal, tripolifosfato de sódio e proteína isolada de soja. 2009. 75f. Dissertação (Mestrado em Ciência de Alimentos) - Programa de Pós-graduação em Ciência de Alimentos, Universidade Federal de Santa Catarina, SC.

BAILEY, F.J. A novel approach to the determination of soya proteins in meat products using peptide analysis. Journal of Science of Food and Agriculture, v.27, n.9, p.827-830, 1976.

BAUBLITS, R.T. et al. Pump rate and cooked temperature effects on pork loins instrumental, sensory descriptive and consumer-rated characteristics. Meat Science, v.72, n.4, p.741-750, 2006. Disponível em: <http://dx.doi.org/10.1016/ j.meatsci.2005.10.006>. Acesso em: 15 jun. 2009. doi: 10.1016/j.meatsci.2005.10.006.

BELLOQUE, J. et al. Analysis of soyabean proteins in meat products: a review. Critical Reviews in Food Science and Nutrition, v.42, n.5, p.507-532, 2002.

BERKOWITZ, D.B.; WEBERT, D.W. Determination of soy in meat. Journal of the Association of Official Analytical Chemists, v.70, n.1, p.85-90, 1987.

BJÖRKROTH, J. Microbiological ecology of marinated meat products. Meat Science, v.70, n.3, p.477-480, 2005. Disponível em: 〈http://dx.doi.org/10.1016/j.meatsci.2004.07.018〉. Acesso em: 15 jun. 2009. doi: 10.1016/j.meatsci.2004.07.018.

BORTOLUZZI, R.C. Marinados. In: OLIVO, R. O mundo do frango: cadeia produtiva da carne de frango. Criciúma: Ed. do autor, 2006. p.473-480.

BRASHEAR, G. et al. Effect of raw material pH, pump level and pump composition on quality characteristics of pork. Journal of Muscle Foods, v.13, n.3, p.189-204, 2002.

BRASIL. MINISTÉRIO DA AGRICULTURA E DO ABSTECIMENTO. Instrução Normativa n.4, de 31/03/2000. Regulamentos técnicos de identidade e qualidade de Carne Mecanicamente Separada, Mortadela, Lingüiça e Salsicha. Diário Oficial da União, seção I, p.6-10, 2000a.

BRASIL. MINISTÉRIO DA AGRICULTURA E DO ABSTECIMENTO. Instrução Normativa n.20, de 31/07/2000. Regulamentos técnicos de identidade e qualidade de Almôndega, Apresuntado, Fiambre, Hambúrguer, Kibe, Presunto Cozido e Presunto. Diário Oficial da União, seção I, p.7-12, 2000 b.

BRASIL. MINISTÉRIO DA AGRICULTURA E DO ABSTECIMENTO. Instrução Normativa n.21, de 31/07/2000. Regulamentos técnicos de identidade e qualidade de Patê, Bacon e Lombo Suíno. Diário Oficial da União, seção I, p.12-15, 2000c.

BRASIL. MINISTÉRIO DA AGRICULTURA E DO ABSTECIMENTO. Instrução Normativa n.22, de 31/07/2000. Regulamentos técnicos de identidade e qualidade de Copa, Jerked Beef, Presunto tipo Parma, Presunto Cru, Salame, Salame tipo Alemão, Salame tipo Calabrês, Salame tipo Friolano, Salame tipo Napolitano, Salame tipo Hamburguês, Salame tipo Italiano, Salame tipo Milano, Lingüiça Colonial e Pepperoni. Diário Oficial da União, seção I, p.15-28, 2000d.

BRASIL. MINISTÉRIO DA AGRICULTURA E DO ABSTECIMENTO. Instrução Normativa n.6, de 15/02/2001. Regulamentos técnicos de identidade e qualidade de Paleta Cozida, Produtos Cárneos Salgados, Empanados, Presunto tipo Serrano e Pratos Elaborados. Diário Oficial da União, seção I, p.6064, 2001.

BRASIL. MINISTÉRIO DA AGRICULTURA, PECUÁRIA E ABASTECIMENTO. Instrução Normativa n.51, de 29/12/ 2006. Regulamento técnico de atribuição de aditivos e seus limites para a categoria 8 - carnes e produtos cárneos. Diário Oficial da União, seção I, p.14, 2007.

BRASIL. MINISTÉRIO DA AGRICULTURA, PECUÁRIA E ABASTECIMENTO. DEPARTAMENTO DE INSPEÇÃO DE PRODUTOS DE ORIGEM ANIMAL. Ofício Circular n.08, de 04/03/2010. Suspensão da elaboração e comercialização de produtos temperados (carcaças, cortes e produtos de aves). Brasília, 2010. Disponível em: <http:// sigsif.agricultura.gov.br.>. Online Acesso em: 18 jun. 2010.

CASTRO, F. et al. Easy determination of the addition of soybean proteins to heat-processed meat products prepared with turkey meat or pork-turkey meat blends that could also contain milk proteins. Food Additives and Contaminants, v.22, n.12, p.1209-1218, 2005. 
CASTRO, F. et al. Determination of soybean proteins in commercial heat-processed meat products prepared with chicken, beef or complex mixtures of meats from different species. Food Chemistry, v.100, n.2, p.468-476, 2007. Disponível em: <http:/ /dx.doi.org/10.1016/j.foodchem.2005.09.067>. Acesso em: 10 fev. 2009. doi: 10.1016/j.foodchem.2005.09.067.

CASTRO-RUBIO, F. et al. Simple and inexpensive method for the reliable determination of soybean proteins in heat-processed meat products: an alternative to the AOAC official method. Journal of Agricultural and Food Chemistry, v.53, n.2, p.220-226, 2005. Disponível em: <http://pubs.acs.org/doi/pdf/ 10.1021/jf049557e>. Acesso em: 29 mar. 2009. doi: 10.1021/ jf049557e

DAGUER, H. Efeitos da injeção de ingredientes não cárneos nas características físico-químicas e sensoriais do lombo suíno. 2009. 187f. Tese (Doutorado em Tecnologia de Alimentos) - Programa de Pós-graduação em Tecnologia de Alimentos, Universidade Federal do Paraná, PR.

DAGUER, H. et al. Detecção de soja pelo teor de isoflavonas em lombo injetado de suíno. Ciência Rural, v.40, n.4, p.990993, 2010a. Disponível em: <http://www.scielo.br/ scielo.php ? script $=$ sci_arttext \& pid =S 0103 $84782010000400039 \& \operatorname{lng}=\mathrm{pt} \& \mathrm{nrm}=\mathrm{iso} \& \ln \mathrm{l}=\mathrm{pt}>$. Acesso em: 09 maio, 2010. doi: 10.1590/S0103-84782010005000046.

DAGUER, H. et al. Perfil eletroforético de lombo suíno adicionado de proteínas não cárneas. Ciência Rural, v.40, n.2, p.404410, 2010b. Disponível em: <http://www.scielo.br/ scielo.php ? script=sci_arttext \& pid=S $0103-$ $84782010000200028 \& \operatorname{lng}=\mathrm{en} \& n \mathrm{n} r \mathrm{~m}=\mathrm{iso} \& \mathrm{t} \operatorname{lng}=\mathrm{pt}>$. Acesso em: 09 maio, 2010. doi: 10.1590/S0103-84782010005000011.

DURAND, P. Tecnología de los productos de charcutería y salazones. Zaragoza: Acribia, 2002. 556p.

DUŠEK, M. et al. Isotachophoretic determination of added phosphate in meat products. Meat Science, v.65, n.2, p.765769, 2003. Disponível em: <http://dx.doi.org/10.1016/S03091740(02)00279-6>. Acesso em: 09 maio, 2009. doi: 10.1016/ S0309-1740(02)00279-6.

GENOVESE, M.I.; LAJOLO, F.M. Determinação de isoflavonas em derivados de soja. Ciência e Tecnologia de Alimentos, v.21, n.1, p.86-93, 2001. Disponível em: <http://www.scielo.br/ scielo.php? script =sci_arttext \& pid=S0101$20612001000100019 \& \operatorname{lng}=\mathrm{pt} \& n \mathrm{rm}=\mathrm{iso} \& \ln \mathrm{g}=\mathrm{pt}>$. Acesso em: 09 abr. 2009. doi: 10.1590/S0101-20612001000100019.

GÓES-FAVONI, S.P. et al. Isoflavonas em produtos comerciais de soja. Ciência e Tecnologia de Alimentos, v.24, n.4, p.582-586, 2004. Disponível em: <http://www.scielo.br/ scielo.php? script $=$ sci_arttext \& pid = S 0101 $20612004000400017 \& \operatorname{lng}=\mathrm{pt} \& \mathrm{nrm}=\mathrm{iso} \& \mathrm{t} \operatorname{lng}=\mathrm{pt}>$. Acesso em: 09 abr. 2009. doi: 10.1590/S0101-20612004000400017.

GONZÁLEZ-CÓRDOVA, A.F. et al. Detección inmunoquímica de la adulteración de chorizo de cerdo com proteínas de soja. Food Science and Technology International, v.4, n.4, p.257-262, 1998.

GOODING, J.P. et al. Characterization of striping in fresh, enhanced pork loins. Meat Science, v.81, n.2, p.364-371, 2009. Disponível em: <http://dx.doi.org/10.1016/ j.meatsci.2008.08.016>. Acesso em: 14 ago. 2009. doi: 10.1016/j.meatsci.2008.08.016.

HAYES, J.E. et al. The effect of enhancement with salt, phosphate and milk proteins on the physical and sensory properties of pork loin. Meat Science, v.72, n.3, p.380-386, 2006. Disponível em: <http://dx.doi.org/10.1016/ j.meatsci.2005.05.009>. Acesso em: 14 ago. 2009. doi: 10.1016/j.meatsci.2005.05.009.

HOOGENKAMP, H.W. Soy protein and formulated meat products. Cambridge: CABI Publishing, 2005. 301p.

JANSSEN, F.W. et al. Detection of wheat gluten, whey protein, casein, ovalbumin, and soy protein in heated meat products by electrophoresis, blotting, and immunoperoxidase staining. Journal of Agricultural and Food Chemistry, v.35, n.4, p.563-567, 1987.

LARREA, V. et al. Changes in proteins during Teruel dry-cured ham processing. Meat Science, v.74, n.3, p.586-593, 2006. Disponível em: 〈http://dx.doi.org/10.1016/j.meatsci.2006.05.009>. Acesso em: 03 set. 2009. doi: 10.1016/j.meatsci.2006.05.009.

LEITNER, A. et al. Identification of marker proteins for the adulteration of meat products with soybean proteins by multidimensional liquid cromatography - tandem mass spectrometry. Journal of Proteome Research, v.5, n.9, p.2424-2430, 2006. Disponível em: <http://pubs.acs.org/doi/ pdfplus/10.1021/pr060145q >. Acesso em: 15 jun. 2009. doi: $10.1021 / \mathrm{pr} 060145 \mathrm{q}$.

MCINTOSH, G.H. et al. Whey proteins as functional food ingredients? International Dairy Journal, v.8, n.5/6, p.425434, 1998.

MELLENTHIN, O.; GALENSA, R. Analysis of polyphenols using capillary zone electrophoresis and HPLC: detection of soy, lupin, and pea protein in meat products. Journal of Agricultural and Food Chemistry, v.47, n.2, p.594-602, 1999. Disponível em: <http://pubs.acs.org/doi/pdf/10.1021/ jf980749h>. Acesso em: 21 abr. 2009. doi: 10.1021/jf980749h.

MILLER, R. Functionality of non-meat ingredients used in enhanced pork. Des Moines: National Pork Board, 1998. 12f. Disponível em: <http://www.meatscience.org/Pubs/ factsheets/functionalitynonmeat.pdf $>$. Online. Acesso em: 18 abr. 2009.

MULTON, J.L. Aditivos y auxiliares de fabricacción en las industrias agroalimentarias. Zaragoza: Acribia, 1988. $680 \mathrm{p}$.

MURPHY-GUTEKUNST, L.; URIBARRI, J. Hidden phosphorus-enhanced meats: part 3. Journal of Renal Nutrition, v.15, n.4, p.E1-E4, 2005. Disponível em: <http:/ /dx.doi.org/10.1053/j.jrn.2005.07.009>. Acesso em: 13 jul. 2009. doi:10.1053/j.jrn.2005.07.009.

OFFER, G.; TRINICK, L. On the mechanism of water holding in meat: the swelling and shrinking of myofibrils. Meat Science, v.8, n.4, p.245-281, 1983. Disponível em: <http://dx.doi.org/ 10.1016/0309-1740(83)90013-X>. Acesso em: 02 nov. 2009. doi: 10.1016/0309-1740(83)90013-X.

OLIVO, R. Tecnologia da extensão cárnea. In: SHIMOKOMAKI, M. et al. Atualidades em ciência e tecnologia de carnes. São Paulo: Varela, 2006. p.175-184. 
PEDERSEN, H.E. Application of soya protein concentrates in processed meat products. Fleischwirtschaft, v.75, n.6, p.798802, 1995.

PEÑA-RAMOS, E.A.; XIONG, Y.L. Whey and soy protein hydrolisates inhibit lipid oxidation in cooked pork patties. Meat Science, v.64, n.3, p.259-263, 2003. Disponível em: <http:/ /dx.doi.org/10.1016/S0309-1740(02)00187-0>. Acesso em: 14 ago. 2009. doi: 10.1016/S0309-1740(02)00187-0.

PIETRASIK, Z. Binding and textural properties of beef gels processed with k-carrageenan, egg albumin and microbial transglutaminase. Meat Science, v.63, n.3, p.317-324, 2003. Disponível em: <http://dx.doi.org/10.1016/S03091740(02)00088-8>. Acesso em: 29 ago. 2009. doi:10.1016/ S0309-1740(02)00088-8.

PIHLANTO, A. Antioxidative peptides derived from milk proteins. International Dairy Journal, v.16, n.11, p.13061314, 2006. Disponível em: <http://dx.doi.org/10.1016/ j.idairyj.2006.06.005>. Acesso em: 13 jul. 2009. doi:10.1016/ j.idairyj.2006.06.005.

PRÄNDL, O. et al. Tecnología e higiene de la carne. Zaragoza: Acribia, 1994. 854p.

SAMMEL, L.M. et al. Identifying constituents of whey protein concentrate that reduce the pink color defect in cooked ground turkey. Meat Science, v.77, n.4, p.529-539, 2007. Disponível em: <http://dx.doi.org/10.1016/j.meatsci.2007.05.007>. Acesso em: 07 abr. 2009. doi:10.1016/j.meatsci.2007.05.007.

SCHIRMER, B.C. et al. Characterization of the bacterial spoilage flora in marinated pork products. Journal of Applied Microbiology, v.106, n.6, p.2106-2116, 2009. Disponível em: < http://www3.interscience.wiley.com/cgi-bin/fulltext/ 122221383/PDFSTART>. Acesso em: 14 ago. 2009. doi: 10.1111/j.1365-2672.2009.04183.x.

SCHLINDWEIN, M.M.; KASSOUF, A.L. Análise da influência de alguns fatores socioeconômicos e demográficos no consumo domiciliar de carnes no Brasil. Revista de Economia e Sociologia Rural, v.44, n.3, p.549-572, 2006

SEIBEL, N.F.; BELÉIA, A.D.P. Carboidratos das fibras de cotilédones e proteínas de produtos derivados de soja (Glycine $\max ($ L.) Merril). Ciência e Tecnologia de Alimentos, v.28, n.3, p.607-613, 2008.

SEKIGUCHI, Y. et al. Analysis of condensed phosphates in food products by ion chromatography with an on-line hydroxide eluent generator. Journal of Chromatography A, v.881, n.1-2, p.639-644, 2000. Disponível em: < http://dx.doi.org/ 10.1016/S0021-9673(99)01278-9>. Acesso em: 03 set. 2009. doi: 10.1016/S0021-9673(99)01278-9.

SHEARD, P.R. et al. Injection of water and polyphosphate into pork to improve juiciness and tenderness after cooking. Meat Science, v.51, n.4, p.371-376, 1999. Disponível em: <http://dx.doi.org/10.1016/S0309-1740(98)00136-3>. Acesso em: 21 abr. 2009. doi:10.1016/S0309-1740(98)00136-3.

SHEARD, P.R.; TALI, A. Injection of salt, tripolyphosphate and bicarbonate marinade solutions to improve the yield and tenderness of cooked pork loin. Meat Science, v.68, n.2, p.305-311, 2004. Disponível em: <http://dx.doi.org/10.1016/ j.meatsci.2004.03.012>. Acesso em: 20 jun. 2009. doi: 0.1016/ j.meatsci.2004.03.012.
SMITHERS, GW. Whey and whey proteins - from 'gutter to gold'. International Dairy Journal, v.18, n.7, p.695-704, 2008. Disponível em: 〈http://dx.doi.org/10.1016/j.idairyj.2008.03.008>. Acesso em: 15 jun. 2009. doi: 10.1016/j.idairyj.2008.03.008.

SOUZA, E.M.T. et al. Electrophoretic analysis to detect and quantify additional whey in milk and dairy beverages. Ciência e Tecnologia de Alimentos, v.20, n.3, p.314-317, 2000.

SZERMAN, N. et al. Effect of whey protein concentrate and sodium chloride addition plus tumbling procedures on technological parameters, physical properties and visual appearance of sous vide cooked beef. Meat Science, v.76, n.3, p.463-473, 2007. Disponível em: <http://dx.doi.org/ 10.1016/j.meatsci.2007.01.001>. Acesso em: 03 jul. 2009. doi: 10.1016/j.meatsci.2007.01.001.

TASKI-AJDUKOVIC, K. et al. Detection of genetically modified organisms in processed meat products on the Serbian food market. Meat Science, v.81, n.1, p.230-232, 2009. Disponível em: <http://dx.doi.org/10.1016/j.meatsci.2008.07.024>. Acesso em: 14 ago. 2009. doi: 10.1016/j.meatsci.2008.07.024.

TERRA, N.N. et al. Emprego de soro de leite líquido na elaboração de mortadela. Ciência Rural, v.39, n.3, p.885890, 2009. Disponível em: <http://www.scielo.br/ scielo.php ? script $=$ sci_arttext \& pid=S 0103 $84782009000300038 \& \operatorname{lng}=p t \& n r m=i s o \& t \operatorname{lng}=p t>$. Acesso em: 03 set. 2009. doi: 10.1590/S0103-84782009000300038.

VALLEJO-CORDOBA, B. et al. Capillary electrophoresis for the analysis of meat authenticity. Journal of Separation Science, v.28, n.9-10, p.826-836, 2005.

VELOSO, A.C.A. et al. Detecção de adulterações em produtos alimentares contendo leite e/ou proteínas lácteas. Química Nova, v.25, n.4, p.609-615, 2002. Disponível em: < http:// www.scielo.br/scielo.php?script=sci_arttext\&pid=S0100$40422002000400016 \& \operatorname{lng}=p t \& n r m=i s o \& t \operatorname{lng}=p t>$. Acesso em: 12 abr. 2009. doi: 10.1590/S0100-40422002000400016.

VERBEKEN, D. et al. Influence of k-carrageenan on the thermal gelation of salt-soluble meat proteins. Meat Science, v.70, n.1, p.161-166, 2005. Disponível em: <http://dx.doi.org/ 10.1016/j.meatsci.2004.12.007>. Acesso em: 05 maio, 2009. doi: 10.1016/j.meatsci.2004.12.007.

XIA, X. et al. Physicochemical change and protein oxidation in porcine longissimus dorsi as influenced by different freeze-thaw cycles. Meat Science, v.83, n.2, p.239-245, 2009. Disponível em: 〈http://dx.doi.org/10.1016/j.meatsci.2009.05.003>. Acesso em: 05 out. 2009. doi: 10.1016/j.meatsci.2009.05.003.

XIONG, Y.L. Role of myofibrillar proteins in water-binding in brine-enhanced meats. Food Research International, v.38, n.3, p.281-287, 2005. Disponível em: <http://dx.doi.org/ 10.1016/j.foodres.2004.03.013>. Acesso em: 17 mar. 2009. doi: 10.1016/j.foodres.2004.03.013.

XU, S.Q. et al. The influence of polyphosphate marination on Simmental beef shear value and ultrastructure. Journal of Muscle Foods, v.20, n.1, p.101-116, 2009.

ZARKADAS, C.G. et al. Evaluating protein quality of model meat/soybean blends using amino acid compositional data. Journal of Agricultural and Food Chemistry, v.41, n.4, p.624-632, 1993. Disponível em: <http://pubs.acs.org/doi/pdf/ 10.1021/jf00028a022>. Acesso em: 04 jan. 2009. doi: $10.1021 /$ jf00028a022. 